\title{
Experimental investigation of Surface Roughness and Cutting force in CNC Turning - A Review
}

\author{
Dhiraj Patel ${ }^{*}$ and R. G. Jivani \\ BVM Engineering College, V V Nagar, Gujarat (India)
}

Received 3 January 2014; Accepted 3 August 2014

\begin{abstract}
The main purpose of this review paper is to check whether quality lies within desired tolerance level which can be accepted by the customers. So, experimental investigation surface roughness and cutting force using various CNC machining parameters including spindle speed $(\mathrm{N})$, feed rate (f), and depth of cut (d), flow rate $(\mathrm{Q})$ and insert nose radius (r). As such, a solemn attempt is made in this paper to investigate the response parameters, viz., Cutting force and Surface Roughness (Ra) a by experimentation on EN 19 turning process. The Design of experiments is carried-out considering Taguchi Technique with four input parameters, namely, spindle speed, feed rate, and depth of cut, flow rate and insert nose radius. The experiments are conducted considering the above materials for L16 and then the impact of each parameter is estimated by ANOAVA. Then the regression analysis is carried-out to find the trend of the response of each material. This experimental study aims at taguchi method has been applied for finding the effect on surface roughness and cutting force by various process parameters. And after that we can easily find out that which parameter will be more affect.
\end{abstract}

Keywords: Community Mining; Label Propagation; Social Network

\section{Introduction}

The challenge of modern machining industries is mainly focused on the achievement of high quality, in term of work piece dimensional accuracy, surface finish. Surface texture is concerned with the geometric irregularities of the surface of a solid material which is defined in terms of surface roughness, waviness, lay and flaws. Surface roughness consists of the fine irregularities of the surface texture, including feed marks generated by the machining process.

\section{Adjustable process parameter}

A. Cutting Speed: Speed (v) is the peripheral speed of the cutter in $\mathrm{m} / \mathrm{min}$. Cutting speed

$(\mathrm{V})=\mathrm{DN} / 1000$,

Where,

$\mathrm{D}=$ work piece diameter in $\mathrm{mm}$,

$\mathrm{N}=$ spindle speed in $\mathrm{rpm}$

B. Feed: It is the distance moved by the tool in an axial direction at each revolution of the work. It is usually expressed in $\mathrm{mm} / \mathrm{rev}$.

C. Depth of cut: It is the thickness of metal removed from the $\mathrm{w} / \mathrm{p}$, measured in a radial direction or It is the perpendicular distance measured from the machining surface to the un machined surface of the w/p or It is the depth of penetration of the tool into the $w / p$ during

*E-mail address: dhiraj_patel27187@yahoo.in ISSN: 1791-2377 @ 2014 Kavala Institute of Technology. All rights reserved. machining. It is usually expressed in $\mathrm{mm}$. The turning operation reduces the diameter of the work piece from the initial diameter Do to the final diameter Df. The change in diameter is actually two times depth of cut, $d=$ Do-Df.

D. Nose radius: Nose radius used for this experiment is 0.4 and 0.8

E. Flow rate: flow of cooling oil on the job is $\mathrm{m} 3 / \mathrm{min}$

\section{Taguchi Method}

Taguchi's approach has been built on traditional concepts of Design of Experiments (DOE), such as Full factorial, fractional factorial design and orthogonal arrays based on signal -to-noise ratio, robust design and parameter and tolerance designs. DOE is a powerful statistical technique introduced by R.A. Fisher in England in 1920s to study the effect of multiple variables simultaneously [Philips (1989)]. Since, the research work concentrates on the experimental work, the number of experiments is to be conducted, the effect of the individual parameters on the turning operation, either independently or combined have to be studied. Therefore, the well known Taguchi technique is chosen and adopted in the present research work. In order to reduce the total number of experiments "Sir Ronald Fisher" has developed the solution: "Orthogonal Arrays". The orthogonal array is a distillation mechanism by which the engineers can select the experimental process. The array allows the researcher engineer to vary multiple variables at one time and obtain the effects such that set of variables has an average and the dispersion. Taguchi employs the design of experiments using specially constructed table, known as "Orthogonal Arrays" (OA) to treat the design process, such 
that the quality is build into the product during the product design stage. Orthogonal Arrays are the special set of Latin squares, constructed by Taguchi to lay-out the product design experiments. The 16 indicates the nine rows, configurations, or prototypes to be tested. Specific test characteristics for each experimental evaluation are identified in the associated row of the table. Thus 'L16 (44) means that sixteen experiments are to be carried-out to study four variables with four levels. The number of experiments is reduced to 16 .

\section{Literature Survey}

A. Lazarevic $2012^{[1]}$ This paper discusses the use of Taguchi method for minimizing the surface roughness in turning polyethylene. The influence of four cutting parameters, cutting speed, feed rate, depth of cut, and tool nose radius on average surface roughness (Ra) was analysed on the basis of the standard L27 Taguchi orthogonal array. The experimental results were then collected and analysed with the help of the commercial software package MINITAB. Based on the analysis of means (ANOM) and analysis of variance (ANOVA), the optimal cutting parameter settings are determined, as well as level of importance of the cutting parameters. The study show that the ANOVA results indicate that the feed rate is far the most significant parameter, followed by tool nose radius, and cutting speed, whereas the influence of depth of cut is negligible.

B. Jitendra $2012^{[2]}$ The purpose of this research paper is focused on the analysis of optimum cutting conditions to get lowest surface roughness in turning ASTM A242 Type-1 ALLOYS STEEL by Taguchi method. Experiment was designed using Taguchi method and 9 experiments were conducted by this process. The results are analyzed using analysis of variance (ANOVA) method. Taguchi method has shown that the cutting speed has significant role to play in producing lower surface roughness about $57.47 \%$ followed by feed rate about $16.27 \%$. The Depth of Cut has lesser role on surface roughness from the tests. The results obtained by this method will be useful to other researches for similar type of study and may be eye opening for further research on tool vibrations, cutting forces etc. The following are conclusions drawn based on the tests conducted on turning ASTM A242 Type-1. ALLOYS STEEL and $250 \mathrm{~mm}$ long with $50 \mathrm{~mm}$ diameter. 1. From the ANOVA, Table 5 and the $\mathrm{P}$ value, the cutting speed is the only significant factor which contributes to the surface roughness i.e. $57.47 \%$ contributed by the cutting speed on surface roughness. 2. The second factor which contributes to surface roughness is the feed rate having 23.46. 3. The third factor which contributes to surface roughness is the depth of cut having $16.27 \%$

C. G. Akhyar, $2008^{[3]}$ Taguchi optimization methodology is applied to optimize cutting parameters in turning Ti$6 \% \mathrm{Al}-4 \% \mathrm{~V}$ extra low interstitial with coated and uncoated cemented carbide tools under dry cutting condition and high cutting speed. The turning parameters evaluated are cutting speed of 55,75 , and $95 \mathrm{~m} / \mathrm{min}$, feed rate of $0.15,0.25$ and $0.35 \mathrm{~mm} / \mathrm{rev}$, depth of cut of $0.10,0.15$ and $0.20 \mathrm{~mm}$ and tool grades of $\mathrm{K} 313$, KC9225 and KC5010, each at three levels. The analysis of results show that the optimal combination of parameters are at cutting speed of $75 \mathrm{~m} / \mathrm{min}$, feed rate of
$0.15 \mathrm{~mm} / \mathrm{min}$, depth of cut of $0.10 \mathrm{~mm}$ and tool grade of KC9225. The cutting speed and tool grade have a significant effect on surface roughness are 0.000 and have a contribution are $47.146 \%$ and $38.881 \%$, respectively. At optimal condition, contribution of each cutting parameter on surface roughness is reached at 20.47 from tool grade, 21.01 from feed rate, 11.54 from depth of cut and 11.17 from cutting speed.

D. Rahul Davis 2013[4] The present work is associated with turning operation of En-19 steel. The paper represents the influences of five different cutting parameters like pressurized coolant jet, rake angle, depth of cut, spindle speed and feed rate on the surface roughness of the En19 steel. In the experiment Taguchi technique was used to calculate the various readings by using MINITAB 15 software. Orthogonal L16 array was used and signal to noise ratio and the analysis of variance (ANOVA) are employed to interpret the cutting parameters. The carbide tipped tool having negative and positive rake angle according to the combination of the experiment was used. The experiment setup included spindle speed of 780 and $1560 \mathrm{rev} / \mathrm{min}$, pressurized coolant jet of 0.5 and 1 bar, rake angle 4 and 7 degrees, depth of cut of 0.5 and $1 \mathrm{~mm}$ and feed rate 0.16 and $0.8 \mathrm{~mm} / \mathrm{rev}$. At last confirmation test was done to compare the value with final outcome to confirm the effectiveness of the surface roughness of En-19 steel.

E. N.H.Rafai [5] This paper presents experimental and analytical results of a preliminary investigation into dimensional accuracy and surface finish achievable in dry turning. The Taguchi method and Pareto ANOVA analysis is used to determine the effects of the three major controllable machining parameters, viz. cutting speed, feed rate and depth of cut on dimensional error, surface roughness and circularity, and subsequently to find their optimum combination. The results indicate that while the cutting parameters have varying influence on the quality characteristics at different levels, the utilization of low feed rate can optimize the dimensional error, surface roughness and circularity of cylindrical component parts concurrently.

\section{Material Selection}

The work piece of $25 \mathrm{~mm}$ diameter and $80 \mathrm{~mm}$ length is used in this experiment. The selected work piece material for this experiment is En19 due to its commercial availability. En19 material is used for axle shaft, connecting rod, gears, high tensile bolt and studs, propeller shaft, joint etc. En19 is typically available in form of bar.

\section{En19 Properties}

The chemical and mechanical properties for En19 are shown in tables below.

\begin{tabular}{c|c} 
Chemical composition of En-19 \\
\hline Component & Amount (wt. \%) \\
\hline Carbon & $0.35-0.45 \%$ \\
Manganese & $0.50-0.80 \%$ \\
Chromium & $0.90-1.50 \%$ \\
Molybdenum & $0.20-0.40 \%$ \\
Silicon & $0.10-0.35 \%$ \\
Phosphorous & $0.035 \% \max$ \\
Sulphur & $0.050 \% \max$ \\
\hline
\end{tabular}


Mechanical properties of En-19

\begin{tabular}{c|r|r|r}
\hline $\begin{array}{c}\text { Mechanical properties of En-19 } \\
\begin{array}{c}\text { Tensile } \\
\left(\mathbf{N} / \mathbf{m m}^{\mathbf{2}}\right)\end{array}\end{array}$ & $\begin{array}{c}\text { Yield } \\
\left(\mathbf{N} / \mathbf{m m}^{\mathbf{2}}\right)\end{array}$ & $\begin{array}{c}\text { Brinell } \\
\text { Hardness }\end{array}$ & $\begin{array}{c}\text { Elongation } \\
(\%)\end{array}$ \\
\hline $925-1000$ & 755 & $269-331$ & 12 \\
\hline
\end{tabular}

\section{Tool Selection}

Carbide inserts CNMG-VF 090304 and CNMG-VF 090308 (ISO catalogue number) is used in turning operation.

Table shows specification for Carbide inserts CNMG-VF 090304 AND CNMG-VF 090308.

\begin{tabular}{c|c|c|c|c}
\hline $\begin{array}{c}\text { ISO } \\
\text { Catalogue } \\
\text { number }\end{array}$ & $\begin{array}{c}\text { l } \\
(\mathrm{mm})\end{array}$ & $\begin{array}{c}\mathbf{d} \\
(\mathrm{mm})\end{array}$ & $\begin{array}{c}\mathbf{t} \\
(\mathrm{mm})\end{array}$ & $\begin{array}{c}\mathbf{r} \\
(\mathbf{m m})\end{array}$ \\
\hline
\end{tabular}

\begin{tabular}{c|c|c|c|c}
\hline $\begin{array}{c}\text { CNMG-VF } \\
090304\end{array}$ & 9.7 & 9.525 & 3.18 & 0.4 \\
$\begin{array}{c}\text { CNMG-VF } \\
090308\end{array}$ & 9.7 & 9.525 & 3.18 & 0.8 \\
\hline
\end{tabular}

\section{Conclusion}

In this study the optimal cutting condition for turning was selected by varying adjustable cutting parameters. With the L16 orthogonal array, experimental runs and determining suitable optimal cutting parameters for surface finish and cutting force. The surface finish achievement of the confirmation runs under the optimal cutting parameters indicated that of the parameter settings used. In this study, taguchi method will apply to produce the best surface roughness in this turning operation. Also, taguchi method is an efficient and effective method for optimizing surface roughness in a turning.

\section{References}

1. A. Lazarević "Study Performance Cutting Parameters Optimization for Surface Roughness in Turning Operation of Polyethylene (PE) Using Taguchi Method", Faculty of Manufacturing Engineering, 2012

2. Jitendra Verma "Turning Pameter Optimization For Surface Roughness Of ASTM A242 TYPE-1 Alloys Steel By Taguchi Method", Mechanical Engineering College Samrat Ashok Technological Institute, M.P, 2012

3. Akhyar, C.H. Che Haron, J.A. Ghani "Application of Taguchi Method in the Optimization of Turning Parameters for Surface Roughness" University Kebangsaan Malaysia,2008

4. Rahul Davis, Vivek John, Vivek Kumar Lomga \& Raja Paul Horo "The Applications Of Taguchi's Optimization Method In Wet Turning Operation Of EN 19 Steel", Faculty of Mechanical Engineering, Uttar Pradesh, 2013

5. N. H. Rafai, M. N. Islam “An Investigation into Dimensional Accuracy and Surface Finish Achievable in Dry Turning: Preliminary Study"

6. Jain R.K. "Production Technology" Khanna Publishers, 2009.

7. Pritam Singh Gill "Geometric Dimensioning and Tolerancing”, S.K. Kataria \& Sons,

8. James D Meadows "Geometric Dimensioning and Tolerancing" Vol.2, Marcel Dekker, Version 2.16

9. Montgomery, D.C., Design and Analysis of Experiments, 5th Edn, John Wiley \& Sons, 2005, pp. 218-456.

10. Schneider, George. "Turning Tools and Operations." American Machinist, January, 2010. 